Comunicar y educar en un mundo hipermediatizado. Pautas para el diseño de narrativas multimodales

Gonzalo Darío Andrés, María Mercedes García

https://perio.unlp.edu.ar/ojs/index.php/question/article/view/4796

Cita sugerida: Andrés, G., y García, M. (2018). Comunicar y educar en un mundo hipermediatizado. Pautas para el

diseño de narrativas multimodales. Question, 1(60), e090. doi:https://doi.org/10.24215/16696581e090

\title{
Comunicar y educar en un mundo hipermediatizado. Pautas para el diseño de narrativas multimodales
}

\author{
Communicate and educate in a mediatized world. Guidelines for the \\ design of multimodal narratives
}

Gonzalo Darío Andrés gonzaloandres4@gmail.com

http://orcid.org/0000-0003-4993-6080

Universidad Nacional de Entre Ríos/ Consejo Nacional de Investigaciones Científicas y Técnicas (Argentina) María Mercedes García 1mariamercedesgarcia@gmail.com

http://orcid.org/0000-0003-3093-494X Universidad Nacional de Entre Ríos (Argentina)

\section{Resumen}

Este artículo presenta pautas metodológicas y tecnológicas para el diseño de narrativas multimodales, desplegadas en diferentes soportes y lenguajes, con fines pedagógicos, informativos o expositivos. Plantea que las lógicas mediáticas devienen en un factor constitutivo de todas las prácticas sociales y que los comunicadores y docentes pueden constituirse como creadores y curadores de contenidos. En este marco, argumenta que la 
noción "narrativas multimodales" es pertinente para pensar la circulación discursiva actual ya que contempla múltiples grados y formas de mediatización.

Palabras clave: Comunicación; educación; multimodalidad; TIC.

\section{Abstract}

This paper presents methodological and technological guidelines for the design of multimodal narratives, displayed in different media and languages, with pedagogical, informative or expositive purposes. It propounds that mass media logics became a constitutive factor of all social practices, so communicators and teachers could be constituted as creators and curators of content. In this framework, it argues that the notion of "multimodal narratives" is pertinent for thinking about the current discursive circulation because it contemplates multiple degrees and forms of mediatization.

Keywords: Communication; education; multimodality; ICT.

Las Tecnologías de la Información y la Comunicación (TIC) configuraron en las últimas tres décadas un entorno socio-técnico de escala mundial. Su expansión implicó no sólo la constitución de la información como un bien con valor de mercado, sino también modificaron las formas de comunicación, las instancias de socialización, las prácticas educativas y las producciones culturales (Castells, 1999).

El uso de las computadoras, tablets y teléfonos celulares permite recibir, crear y enviar información simultáneamente. Esto es, posibilitan a los sujetos operar en instancias de producción y de reconocimiento de manera alternada (Verón, 2013). Hoy una persona con ciertas habilidades digitales puede diseñar, componer, editar, o remixar contenidos y ponerlos en circulación en la red. Esto significa que la convergencia tecnológica habilitó además una convergencia de las prácticas (Jenkins, 2008), lo cual ha redefinido el escenario sociocultural e infocomunicacional en las prácticas y organizaciones sociales.

En este marco, se parte del presupuesto de que comunicadores y docentes pueden ser considerados como creadores y curadores de narrativas innovadoras en sus ámbitos profesionales. Por lo tanto, se presentan pautas -de orden metodológico y tecnológico- para el diseño, creación y distribución de narrativas multimodales que tienen como objetivo contar 
historias noticiosas, impulsar la creación colectiva de saberes, presentar historias de vida o exponer temáticas.

Más allá de los grados y formas de mediatización existentes en diversos contextos, se concibe que es posible diseñar y desarrollar producciones tecnológicas y textuales de carácter multimodal, en diversos formatos y con la posibilidad de integrar soportes físicos y digitales en una misma narrativa.

¿Cómo se diseñan narrativas multimodales en contextos comunicacionales, periodísticos o educativos en la actualidad? ¿Existen criterios generales de diseño de narrativas multimodales que contemplen los diversos grados y formas de mediatización? Y en esa línea, ¿cuáles serían las pautas y criterios de producción y distribución de contenidos que combinen la presencialidad física, la interactividad virtual y los soportes analógicos y digitales? Tales son los interrogantes que se plantean.

\section{Perspectiva teórica}

Las pautas para el diseño, creación y distribución de narrativas multimodales que aquí se presentan son resultado de una integración de distintas miradas teóricas: la socio-semiótica (Drigo, 2007; Verón, 2013; Marín Ossa, 2015), la cibercultura (Levy, 2007; Jenkins, 2008; van Dijk, 2016), la tecnología educativa (Maggio, 2016), las narrativas transmedia (Scolari, 2013; Vassallo de Lopes y Orozco Gómez, 2014), la educomunicación (Kaplún, 2002) y la multimodalidad (Cope y Kalantzis, 2010; Kress, 2010).

En principio, siguiendo a Prigogine y Stengers (1979) y Verón $(2013,2015)$, se concibe la mediatización como un sistema auto-organizante, cuya historia es un proceso no-lineal que se va configurando mediante la relación de diversos elementos del entorno socio-tecnológico en el que se desenvuelve. Es decir, que la configuración y materialización de fenómenos semióticos constituye una dimensión antropológica del ser humano y, por tanto, su historia podría rastrearse desde la aparición del Homo Sapiens.

Este proceso de larga duración -que se originó con las primeras herramientas y la invención del habla- alcanzó un nuevo nivel de complejidad en el siglo XX con los medios masivos de comunicación y se profundizó con la expansión de las tecnologías digitales e informáticas (Hjarvard, 2008, 2016).

Estas innovaciones técnicas habilitaron una ruptura de escala en los procesos de producción y circulación de contenidos y saberes (Jenkins, 2008; Verón, 2013), que se manifiesta, por 
ejemplo, en la conectividad, la movilidad, la miniaturización y personalización de los aparatos, la influencia de los algoritmos en los dominios culturales y los patrones de consumos.

Todas estas transformaciones socio-técnicas tienen dos grandes consecuencias. Por un lado, la informatización produjo un cambio en la matriz general de la producción y distribución de la información. Los medios de comunicación tradicionales (gráfica, radio, TV) comenzaron a adecuar -con diversos niveles de éxito- sus modelos de negocios, rediseñar sus plataformas institucionales y competir con empresas que distribuyen contenidos (Google, Facebook) (Mendonça Jorge, 2013; Masip, 2016; Nafría, 2017). Las compañías de broadcasting ahora conviven y compiten con sitios web y redes sociales en el establecimiento de la agenda setting y definen los frames narrativos en la sociedad.

Por otro lado, la informatización atraviesa todos los dominios, procesos y conceptos de la cultura, la política y la economía. Ahora los datos son algoritmos alojados en dispositivos, entonces la lógica informática influye en la creación de discursos y contenidos simbólicos. Por lo que, tanto la ontología como la epistemología y la pragmática de la informática, influyen en la cultura (Manovich, 2006). En efecto, no puede entenderse ninguna práctica cultural contemporánea si no se conoce la configuración informática que la compone, ya que el software penetra las técnicas de control, representación, simulación, y análisis, y las prácticas de escritura e interacción (Manovich, 2013).

Por tanto, con la expansión tecnológica no sólo se está produciendo una reconfiguración hacia adentro de las empresas mediáticas, sino también de las organizaciones educativas, culturales y políticas (Marín Ossa, 2015; Hjarvard, 2016). Desde esta perspectiva, se plantea que la mediatización se caracteriza por el hecho de que la lógica comunicativa influye en todas las instituciones sociales y transforma las condiciones de interacción social (Verón, 2013; Hepp, Hjarvard y Lundby, 2015).

Los medios y tecnologías de la información y la comunicación atraviesan cada vez más la praxis cotidiana, laboral y educativa. Así, en el actual mundo hipermediatizado las habilidades digitales y comunicacionales se convierten en una necesidad para aquellos que se desempeñan en distintos marcos institucionales. Con lo cual, en las sociedades contemporáneas el "componente comunicacional" no es un atributo propio solamente de los mass media sino que forma parte de todas las prácticas sociales.

El proceso de mediatización genera, entonces, que las lógicas mediáticas devengan un factor constitutivo de las instituciones políticas, culturales y educativas (Verón, 2013; Hjarvard, 2008; van Dijk, 2016). De modo que es pertinente entender a docentes, periodistas y comunicadores 
como creadores y curadores de narrativas multimodales que propician la interactividad, el descubrimiento y la creación conjunta de informaciones y saberes.

Por consiguiente, se argumenta que -así como las lógicas mediáticas atraviesan todas las prácticas sociales- es posible delinear pautas para la creación y distribución de narrativas que funcionen en diferentes marcos institucionales, con distintos objetivos comunicacionales 0 educativos. Este enfoque permitirá elaborar una aproximación conceptual a las narrativas multimodales que se configuran a partir de las emergentes capacidades que brindan las TIC para repensar los modos de comunicar, informar, enseñar, aprender, componer y acceder al conocimiento.

\section{Comunicar y educar en la actualidad}

Las TIC modificaron las condiciones de circulación de informaciones y contenidos. Actualmente se requiere de habilidades para la búsqueda, selección, edición y curación de la gran cantidad de información que se dispone. Las exploraciones, lecturas, montajes y recombinaciones de textos, imágenes y sonidos son un rasgo constitutivo de las prácticas comunicacionales, periodísticas y pedagógicas. Por eso es preciso reflexionar sobre las estrategias y las formas de acceder y producir contenidos y saberes en los ámbitos laborales y profesionales de la comunicación y la educación.

\section{La transformación del trabajo periodístico}

Los sitios web, las redes sociales y la big data transformaron la práctica periodística y los modelos de negocios de los medios de comunicación. En el ecosistema infocomunicacional se multiplicaron los soportes y plataformas informativas, los medios tradicionales conviven con los entornos virtuales, y la virtualidad potencia la circulación de información.

En contextos de reconocimiento, las audiencias tienen cada vez más preponderancia en los procesos de obtención y chequeo de datos, el comentario de la noticia y la circulación de informaciones. Las personas disponen de una mayor oferta informativa, no sólo por parte de empresas mediáticas sino también de sus familiares, amigos y allegados en las redes sociales. Allí se marcan tendencias, comentan las historias noticiosas y hablan sobre los medios y periodistas (Raimondo Anselmino, 2012; Rost, Bernardi y Bergero, 2016). 
En contextos de producción, la utilización de computadoras y smartphones complejizó la producción informativa. Los periodistas disponen de una cantidad ingente de fuentes que les permite chequear, completar y enriquecer sus datos (Masip, 2013). Asimismo, debido a la convergencia tecnológica, hoy es posible realizar gran cantidad de actividades con un mismo dispositivo: una persona puede asumir el rol de periodista, fotógrafo y camarógrafo al mismo tiempo (aunque eso no significa que sepa hacerlo de manera adecuada). Dicho de otro modo, estamos ante una transformación integral del oficio periodístico: la convergencia tecnológica generó una convergencia de las prácticas y una centralización de la actividad y la producción en internet, más allá de que la empresa periodística cuente también con otros medios en distintos formatos (radio, TV, diario, revista).

Así, las TIC habilitan la presentación de historias noticiosas de carácter multimodal, vinculando formatos y prácticas propias de la virtualidad con soportes mediáticos tradicionales. Lo cual exige, en términos conceptuales, repensar la función e identidad de los medios de comunicación y, en términos operativos, contar con habilidades para la creación y edición de textos, imágenes, audios, videos y programación informática.

\section{La virtualización de la enseñanza y el aprendizaje}

Cuando se hace referencia a la virtualización de la educación generalmente se piensa en proyectos de educación a distancia. Sin embargo, en la actualidad se visualizan escenarios híbridos donde es posible pensar nuevas didácticas, contenidos, metodologías, actividades y formas de evaluación.

Principalmente en ámbitos de educación superior -sea a distancia o no-, el contacto entre docentes, estudiantes y el personal de gestión y administrativo está mediatizado por soportes técnicos que pueden ser gráficos, visuales, audiovisuales, auditivos, informáticos. Se establece así un diálogo didáctico mediatizado, conformado por la presencialidad física con la virtualidad que reconfigura los propósitos socio-educativos (Turpo Gebera, 2013; Marín Ossa, 2015).

La digitalización permite a los docentes y estudiantes gestionar su propia relación con el otro y con el saber. Hoy es posible generar ambientes que promuevan la interactividad y la creación conjunta de conocimientos. Esto supone que los docentes tengan que planificar las instancias de producción, comunicación y evaluación de cada curso o asignatura contemplando esta dinámica integrada.

Hasta hace unas décadas, los docentes configuraban la narrativa de su clase apoyándose en manuales, diccionarios, enciclopedias y libros impresos. En la actualidad, con la convergencia 
de las prácticas sociales, también cuentan con los buscadores de internet, que ofrecen un exceso informativo sobre casi cualquier temática. Incluso, internet permite interactuar con grupos de trabajo especializados en temas específicos o encontrar tutoriales e instructivos para resolver dudas o realizar actividades. Más que buscar y encontrar datos, el desafío actual en los ámbitos educativos consiste en seleccionar y analizar críticamente la información disponible, así como saber editarla, intervenirla y recrearla. Esta situación le exige al docente saber seleccionar y editar y, de ese modo, convertirse en curador de contenidos.

Desde un punto de vista comunicacional y pedagógico, los recursos educativos digitales pueden ser entendidos como materiales de apoyo que comunican contenidos para facilitar el aprendizaje, considerando contextos, habilidades y perfiles de docentes y estudiantes. Esta perspectiva habilita repensar la mediatización de la educación desde una mirada comunicológica, que integre los modos y las formas en que los sujetos producen el lazo social y sus narraciones mediante múltiples entornos y lenguajes (Kaplún, 2002).

En este contexto, el interrogante sobreviene en cómo generar estrategias educativas en un mundo hipermediatizado, cuando ya no alcanza con compartir contenidos con los estudiantes en un entorno virtual o blog. Quizás la estrategia pedagógica radique en la habilidad comunicacional de proponer actividades, contenidos y recursos en una trama narrativa multimodal.

\section{Las narrativas multimodales}

En los últimos años hubo un progresivo interés por las narrativas transmedia. Éstas presentan dos características centrales: 1. los fragmentos del relato se desarrollan en distintos soportes (libros, películas, series, videojuegos) y se relacionan de manera complementaria y sincronizada; 2. los fans acompañan la historia y forman parte de ella, ya que estas narrativas apuestan a la intervención-producción del público seguidor.

En los últimos años se ha investigado sobre este tipo de producciones (Jenkins, 2008; Scolari, 2013; Vassallo de Lopes y Orozco Gómez, 2014). Puntualmente, se realizó una mapeo general de los temas, enfoques y autores que se dedican a este tipo de estudios, donde prevalecen experiencias relacionadas en su mayoría a la industria cultural (Scolari, 2013) y se compilaron casos y experiencias de periodismo transmedia en Argentina (Rost, Bernardi y Bergero, 2016; Irigaray y Lovato, 2017). 
Sin embargo, resulta más difícil hallar estudios sobre casos que no sean en contextos mediáticos o de consumo masivo. En efecto, desde la economía política de la comunicación, se podría decir que este tipo de narrativas funcionarían como estrategias comerciales de las industrias del entretenimiento o empresas periodísticas para diversificar su público.

Por eso aquí se propone pensar en prácticas innovadoras en ámbitos educativos y comunicacionales más allá de las lógicas de las industrias culturales. De modo que serían, en estos casos, diversos profesionales quienes potencien sus aptitudes y habilidades para diseñar tramas narrativas a partir de contenidos y recursos disponibles.

En ese marco, aquí se retoman conceptualizaciones sobre la multimodalidad, nacidas al calor de los estudios literarios, semióticos y cognitivos a lo largo del siglo XX para referirse a las prácticas de comunicación y educación que emplean recursos textuales, sonoros y visuales. Desde esta perspectiva, se podrían relacionar las actuales experiencias propias de la presencialidad física, los soportes analógicos con las tecnologías y las dinámicas y espacios de la virtualidad (sitios web, redes sociales y recursos disponibles en internet).

Así, se conciben las narrativas multimodales como relatos que establecen conexiones entre distintos elementos de una narración y, por eso mismo, articulan contenidos diversos en una trama narrativa más amplia. "Nos encontramos en el epicentro de un cambio sísmico en las comunicaciones, desde un mundo narrado a través del medio de la escritura en una página de libro, diario o revista, hacia un mundo mostrado por medio de lo visual en la pantalla. En la página tradicional del texto escrito había una linealidad fascinante" (Cope y Kalantzis, 2010: 98).

Dado que una persona con ciertas habilidades digitales puede diseñar y editar contenidos y ponerlos en circulación en la red, se propone la construcción de narrativas multimodales con las siguientes características: son expositivas, creativas y/o argumentativas; se despliegan en diferentes soportes y lenguajes; tienen un carácter hipertextual e hipermedial; y son posibles de utilizar como estrategia pedagógica, para exponer temáticas o para contar historias noticiosas. La actual presencialidad físico-virtual permanente permite que las prácticas comunicacionales y pedagógicas en diversos marcos institucionales combinen encuentros presenciales con interacciones virtuales, soportes digitales y analógicos, y lenguajes y tecnologías diferentes. La construcción de narrativas multimodales implica la creación y selección de materiales y la definición de metodologías comunicacionales y pedagógicas acorde a las características y necesidades de los destinatarios (colegas, estudiantes, público general). En ese marco, es posible diseñar experiencias que impulsen la difusión de información, el aprendizaje, la 
comprensión, la circulación de contenidos y la producción de saberes que combinen la corporalidad física y virtual con soportes impresos y digitales.

Con todo, se propone la noción de narrativa multimodal para incorporar las múltiples formas y grados de mediatización con los distintos soportes y lenguajes disponibles para informar, comunicar, enseñar y aprender en el siglo XXI.

\section{Pautas para crear narrativas multimodales}

La integración de TIC en los ámbitos laborales y profesionales habilitó tendencias innovadoras en las prácticas pedagógicas, comunicacionales y periodísticas. Las actuales condiciones de producción, circulación y acceso de contenidos y saberes permiten pensar la configuración textual y tecnológica de narrativas multimodales.

Por eso se concibe a los docentes y comunicadores como creadores, editores y curadores de contenidos capaces de componer una estructura estética o narrativa. Con la edición y la curaduría se puede diseñar una lógica de sentido que ordene cierto recorrido, direccione la lectura, o proporcione una secuencia con fines informativos, educativos o estéticos.

A continuación, entonces, se proponen pautas para el diseño y la producción de narrativas multimodales para informar, enseñar, aprender y componer en el actual contexto físico-virtual.

\section{Diseñar contenidos hipermediales}

Si bien actualmente la noción "hipermedia" puede resultar obsoleta, aún es efectiva para describir las composiciones integradas por distintos lenguajes textuales, sonoros, audiovisuales e informáticos.

La propuesta, entonces, es diseñar contenidos hipermediales que articulen múltiples lenguajes y que aporten a la construcción de narrativas para la secuencia de una clase, el desarrollo de historias noticiosas o la creación estética. Dichas narrativas pueden pensarse de manera físicovirtual, y presentarse en articulación con recursos digitales o materiales impresos.

Esto implicaría, en cierta forma, otorgarle mayor relevancia a contenidos visuales en detrimento de los textos escritos. "Esta complejidad decreciente de lo escrito, sin embargo, se ve compensada por una multimodalidad cada vez más compleja" (Cope y Kalantzis, 2010: 98). Quizás las producciones pueden ser concentradas en pocos párrafos atractivos y contundentes y luego focalizar en otro tipo de lenguajes. 
Para el ámbito del periodismo, implica apuntar a contar historias, eventos o acontecimientos con imágenes. Hasta hace unas décadas, en los medios tradicionales las fotos o ilustraciones acompañaban a los textos; ahora las imágenes son centrales en las historias noticiosas.

En términos pedagógicos, se recomienda producir infografías y presentaciones visuales para la resignificación de los contenidos trabajados, y proponer imágenes, subtitulados y voces en off que tengan capacidad explicativa sobre los temas trabajados. Estos recursos y contenidos hipermediales pueden facilitar aún más el proceso de enseñanza y aprendizaje.

\section{Diseñar contenidos hipertextuales}

La estructura hipertextual se compone de una multiplicidad de referencias cruzadas mediante hipervínculos electrónicos. Los sitios web se caracterizan de ese modo: allí se entrelazan contenidos vinculados entre sí mediante links, conformando una red, y logrando que cada hipervínculo permita múltiples recorridos.

Estas estructuras reticulares transforman los roles del autor y el lector (Vanderdorpe, 2003). Los procesos de escritura y lectura hipertextuales se caracterizan por la fragmentación y la yuxtaposición de diversos formatos: tienen un carácter reticular, descentralizado y multidireccional. La navegación dinámica y el enlace a nuevos materiales aumentan la entropía de una trama narrativa. Los contenidos producidos se enlazan entre sí, generando un dinamismo permanente.

La estrategia de comunicación de un diseño hipertextual de la narración podría potenciar la circulación de información, la elaboración de recursos digitales y/o la mediatización del proceso de enseñanza y aprendizaje. Se trata de vincular distintos materiales y articular varios modos de aprendizaje en una misma narración: soportes físicos y digitales, participación de los lectores, reflexión en profundidad, integración de tecnologías, ejercicios colaborativos, y variedad de géneros y discursos (Cope y Kalantzis, 2010).

\section{Diseñar contenidos responsivos}

En lo que respecta a los sitios web, es necesario diseñar plataformas virtuales y contenidos digitales que sean responsivos. Es decir, que se adapten automáticamente al tamaño de la pantalla de cualquier dispositivo desde el que se acceda (computadora, tablet y celular). Esta técnica de diseño web busca la correcta visualización de una misma página en distintos dispositivos e implica repensar la manera de exponer las temáticas o contar las historias 
noticiosas, así como el diseño de la experiencia de usuario, la estrategia pedagógica y la usabilidad y accesibilidad de los recursos y materiales.

\section{Diseñar contenidos y tecnologías accesibles}

La accesibilidad web suele definirse como la posibilidad de que no sólo las personas con discapacidad visual puedan navegar por la red, sino también puedan verse favorecidos los adultos mayores, las personas con bajo nivel de alfabetización digital y aquellos con mala conectividad y/o que utilizan tecnologías obsoletas (W3C, 2005).

La Web Accessibility Initiative (https://www.w3.org/WAl) promueve soluciones de accesibilidad web para que los contenidos, aplicaciones y navegadores sean accesibles para personas con discapacidades. Establece cuatro principios fundamentales para la accesibilidad del contenido (perceptible, operable, comprensible, robusto) que sirven para comprender los criterios de conformidad e implementación. Lograr la compatibilidad y accesibilidad socio-tecnológica se basa, entonces, en generar condiciones de reconocimiento para todos los sujetos involucrados. Desde esta perspectiva, es fundamental el diseño de tecnologías y contenidos que contemplen las distintas subjetividades y la disponibilidad tecnológica. Concretamente, se trata de producir contenidos en formatos y soportes que sean accesibles para todos. Por ejemplo, todo objeto digital debe poseer una descripción a los fines de que pueda ser leído por un lector de pantalla, o los videos deben estar subtitulados para que puedan ser vistos y comprendidos en computadoras y teléfonos celulares. Estos aspectos contribuyen con la accesibilidad, mejora la cognición y colabora con el proceso de aprendizaje.

\section{Diseñar contenidos de calidad}

La sobreabundancia de información que circula en internet obliga a las instituciones -ya sean periodísticas o educativas- a ofrecer contenidos de calidad. En este contexto, se valora en los comunicadores y docentes las habilidades comunicativas y la capacidad y criterio para crear y articular tramas narrativas con contenidos propios o reutilizables. Es aquí, entonces, donde se evalúa la figura del creador-curador, que realiza una curaduría de contenidos pero también asume un rol de autoría (Schwartzman y Odetti, 2011), ya que se expresa través de su selección y articulación entre los materiales.

En la práctica periodística, los medios deben buscar el modo de seguir siendo imprescindibles para su audiencia ofreciendo historias noticiosas de calidad, bien contadas y atractivas (Nafría, 
2017). Esto implica otorgar al público un valor agregado periodístico, sorprenderlo continuamente con contenidos propios y diferenciales, brindar una mirada diferente sobre los temas. Esas estrategias pueden ser opción para generar una mayor demanda de información fiable y contrarrestar la circulación de fake news.

Con respecto a la práctica educativa, la innovación pedagógica se concibe desde la creación de contenidos originales y de calidad (por parte de los docentes y estudiantes), a los fines de exponer temáticas, analizar problemas, o establecer relaciones complejas entre distintos elementos. Desde esta perspectiva, el docente actúa como un curador de contenidos (Maggio, 2016) que busca información, la clasifica, ordena, rediseña y luego comparte lo que considera pertinente para sus clases. En la virtualización de la enseñanza, se trata de generar ambientes donde las personas puedan recuperar y resignificar contenidos y hacer sus propias creaciones.

\section{Trabajar de modo inter y multidisciplinario}

La colaboración y el trabajo conjunto se consideran fundamentales para atender la multiplicidad de demandas y habilidades requeridas en la producción de narrativas multimodales. Es preciso conformar equipos de trabajo compuestos por distintos especialistas, o bien desarrollar perfiles profesionales con habilidades para atender distintas demandas. Esto es, pensar en la formación académica y laboral de los comunicadores y educadores de una manera integral que les permita crear y componer contenidos en diversos soportes y lenguajes.

En el caso específico de los medios, es preciso que los periodistas, editores gráficos, diseñadores y programadores trabajen de manera colaborativa en los proyectos informativos, que se implementan cada vez más de manera convergente y se difunden en redes sociales. El éxito de los productos y servicios digitales depende de la participación activa, durante todas las fases del proceso, de los profesionales de distintos departamentos: redacción, producto, tecnología, diseño, marketing (Mendonça Jorge, 2013; Masip, 2016; Nafría, 2017).

En el caso de los ámbitos educativos de nivel superior se propone implementar metodologías de enseñanza y aprendizaje basada en la conformación de grupos para la realización de proyectos, resolución de problemas y la producción y apropiación de contenidos y saberes en distintos formatos y lenguajes (Turpo Gebera, 2013; Maggio, 2016).

Si se piensa en la complejidad técnica y pedagógica del proceso, puede decirse que el desarrollo de entornos y contenidos educativos digitales constituye una actividad donde tienen que intervenir equipos conformados por profesionales y expertos en ámbitos y materias muy diferentes: docentes, tutores, gestores, programadores y diseñadores visuales. Esto se debe a 
que la trama narrativa, la estrategia pedagógica y la estructura tecnológica y textual de los recursos deben abordarse articuladamente para que potencien su capacidad educativa.

La apuesta sería, entonces, conformar equipos interdisciplinarios y formar profesionales que dispongan de habilidades y fundamentos técnicos, comunicativos, estéticos y pedagógicos en la puesta en obra de proyectos orientados a la innovación educativa, la alfabetización multimodal y la apropiación social de la información y del conocimiento en el actual contexto físico-virtual.

\section{Pautas para distribuir narrativas multimodales}

Una característica del actual mundo hipermediatizado es que la producción y circulación de contenidos y saberes se establece mediante las configuraciones textuales y tecnológicas de la informática. Las TIC se volvieron cruciales para la búsqueda de datos, las relaciones interpersonales, la circulación de discursos, los consumos culturales, los modos de informarse, la participación política, y la producción y apropiación de conocimiento (Castells, 1999).

Las personas -fundamentalmente los jóvenes- no "buscan" noticias sino que éstas "aparecen" en sus redes sociales (Boczkowski, Mitchelstein y Matassi, 2018). Es decir, acuden menos a los medios de comunicación en busca de información porque, en la mayoría de los casos, las encuentran en las redes sociales. "La socialidad y la creatividad son fenómenos que ocurren mientras las personas están ocupadas en su vida cotidiana" (van Dijck, 2016: 21). Por eso las interacciones son intersticiales, breves, interrumpidas y parciales (Igarza, 2009) y las lecturas se caracterizan por el zapeo, las bifurcación, la "navegación" (Albarello, 2011).

Dado este contexto, uno de los desafíos de los diseñadores de narrativas digitales y multimodales es captar la atención de un lector distraído y rodeado de múltiples estímulos. En este marco, las lecturas simultáneas y recortadas pueden ser guiadas por narrativas que incluyan diferentes soportes y lenguajes.

A continuación se proponen algunas pautas para la distribución de tramas narrativas multimodales para comunicar, informar, enseñar, aprender y componer. En esa dirección, se concibe a comunicadores y educadores como gestores de comunidades virtuales y dinamizadores de debates y experiencias creativas.

\section{Estrategias: digital first y clase invertida}


El diario New York Times implementó hace más de una década la estrategia digital first, que consiste en centralizar y jerarquizar contenidos disponibles en internet para luego lanzarlos 0 publicarlos en diferentes soportes web y en papel (Nafría, 2017). De este modo, se invierte la lógica tradicional de difusión mediática que se basaba en publicar primero en el diario impreso y luego replicar en la web. La estrategia denominada digital first invierte la lógica tradicional de difusión mediática ya que exige sostener un núcleo creativo sólido que se expanda y articule en diferentes medios y soportes, aprovechando sus especificidades. De acuerdo con Nafría (2017), esta estrategia puede implementarse en todos los medios de comunicación, más allá de su tamaño, especificidad y origen (gráfica, radio, TV o web).

$Y$, siguiendo esa lógica, dicha estrategia puede abordarse en otras instituciones o en propuestas educativas virtuales o semipresenciales, en las que los docentes tengan como desafío diseñar entornos virtuales de aprendizaje, jerarquizando temas y tópicos, promoviendo la indagación, la búsqueda de material y la producción colaborativa. Es decir, es posible la puesta en obra del formato de "clase invertida", que consiste en desarrollar una propuesta pedagógica en la virtualidad que focalice en un tema y proponga actividades y resolución de problemas, destinando los encuentros presenciales para la discusión y la resolución de dudas y consultas. De este modo, los estudiantes pueden abordar los recursos y la bibliografía alojados en el aula virtual cuantas veces sea necesario y en su propio tiempo, y la modalidad práctica se destinará al tiempo de la clase presencial, de manera que el docente puede estar presente y coordinar en la construcción del conocimiento. Por lo que el profesor ya no estaría en el centro de atención sino que actuaría como un facilitador del proceso, siendo el estudiante el protagonista -consciente y responsable- de su propio aprendizaje.

En efecto, centralizar contenidos en un entorno virtual y luego distribuirlos en diferentes soportes analógicos y digitales es el objetivo principal de la estrategia digital first, y del formato clase invertida. La adopción de esta práctica exige identificar el rol de cada soporte y lenguaje de manera que se complementen con otros para conformar una trama narrativa y potenciar cada materialidad discursiva.

Así, pues, es preciso contar con un entorno virtual propio o bien utilizar servicios de almacenamiento en la nube, a los fines de disponer de un repositorio con materiales y recursos educativos. Porque se trata de construir narrativas multimodales creando contenidos nuevos 0 utilizando los que están disponibles en internet, centralizar recursos y materiales (propios o ajenos) en un entorno virtual o en un sitio web para luego vincularlos con encuentros presenciales y soportes analógicos o impresos. 


\section{Dialogar con otros y gestionar comunidades}

La distribución de narrativas multimodales está estrechamente relacionada al tipo de sociabilidad contemporánea, estructurada por una presencialidad físico-virtual permanente. Esta situación exige a los creadores de narrativas con fines periodísticos, educativos, estéticos $\mathrm{u}$ organizacionales gestionar comunidades en entornos virtuales y redes sociales (un rol que, en términos de la mercadotecnia, se denomina community manager). Para ello es preciso aprender a ser receptivos, generar empatía y entablar diálogos con otros para conocer sus ideas, intereses e inquietudes.

En los entornos virtuales dedicados a la circulación y apropiación social de la información y/o el conocimiento es indispensable no sólo la producción de datos y saberes sino también la gestión de comunidades y espacios de interacción. Esto implica que las personas se integren a una comunidad en la que puedan informarse, conocer, aprender, compartir informaciones, saberes y sentires del ambiente que habitan. En términos organizacionales, esto significa que las instituciones mediáticas y educativas tienen que adoptar cierto nivel de apertura e intercambio para constituirse en referentes de opinión.

El monitoreo, la investigación, los tipos de búsquedas y los comentarios sobre las informaciones permiten conocer ideas, gustos e intereses del público y, de esa forma, saber qué tipo de contenidos e historias noticiosas prefieren. Para eso es necesario anticiparse y reconocer las inquietudes y experiencias de los otros. Este tipo de competencias son tan importantes en el desarrollo de un gestor de comunidades de práctica como tener habilidades digitales. "Los nuevos entornos tecnológicos aparecen entramando los modos en los que el conocimiento se construye pero también aquellos a través de los cuales se difunde" (Maggio, 2016: 48).

En un contexto de circulación de fake news, crisis de credibilidad de las instituciones mediáticas y educativas, exceso de información circulante y discusión sobre la autoridad docente, resulta fundamental generar empatía con los destinatarios para fortalecer los intereses comunes. Los medios de comunicación están sostenidos en la opinión y seguimiento de su público, así como los procesos educativos se basan en el comentario de los otros, tanto de los docentes como compañeros. Las personas aprenden y se informan en colaboración, con la ayuda y los aportes de otros.

Se propone, pues, contemplar las formas de circulación y recepción de narrativas multimodales para conocer los hábitos, comportamientos, requerimientos y necesidades de los destinatarios y ofrecerles una experiencia comunicacional, educativa y estética enriquecida que contemple 
su aquí y ahora. El atributo comunicacional propio de un docente, periodista o comunicador institucional no se basa sólo en la transmisión de datos sino que actúa como dinamizador de actividades y saberes para resignificar sentidos y expresar un modo de ser y estar en el mundo.

\section{Discusión y prospectiva}

El crecimiento escalar de la mediatización de escala global que configuró la expansión de TIC influye de manera diferente en las diversas organizaciones a nivel local. Con ello, la lógica mediática y comunicacional está atravesando todas las prácticas, procesos y fundamentos de las instituciones sociales.

En ese contexto es pertinente que sujetos con diferentes perfiles profesionales dispongan de habilidades para la comunicación interpersonal, la selección de información, la producción de contenidos y el uso de tecnologías informáticas y digitales. Este nivel y tipo de experticia ya no se presenta como una opción en el actual contexto físico-virtual, sino como una necesidad para todas las instituciones sociales, culturales y políticas. Actualmente es preciso saber producir contenidos en múltiples formatos, lenguajes y soportes. La lectoescritura impresa, que fue hegemónica durante el proceso de alfabetización moderno, hoy convive con lenguajes audiovisuales e informáticos.

En esa dirección, aquí se presentaron pautas para el diseño, creación y distribución de narrativas multimodales en contextos periodísticos y de educación superior. Aunque parezcan sencillas o genéricas, se trata de poner de manifiesto las características estructurales de los procesos de composición, más allá de las innovaciones técnicas, las modas culturales, las tendencias mediáticas o el interés académico por algunos tópicos o tecnologías particulares.

Se plantea que -más allá de las finalidades, soportes o lenguajes empleados con cada caso particular- es posible delinear pautas para la producción y distribución de contenidos y saberes en un mundo hipermediatizado. En efecto, se proponen pautas tecnológicas y metodológicas de carácter transversal y genérico para el diseño de narrativas multimodales que ponen énfasis en las prácticas de los sujetos dedicados a la comunicación y la educación.

Estas pautas son el resultado de un proceso de reflexión conceptual y la articulación de teorías y prácticas disímiles, pero que tienden a una convergencia -o por lo menos a un acercamientooperativo y praxiológico. Se argumenta que la noción de "narrativa multimodal" es más flexible que "narrativa transmedia" y "narrativa digital" (digital storytelling), por tres motivos: 
1. no requiere de la existencia de una comunidad de fans que colaboren con el crecimiento del relato, aunque pueda tener un carácter interactivo;

2. incluye la presencialidad física y virtual y los formatos digitales y analógicos dentro de la trama; y

3. pueden ser desarrolladas por una persona con propósitos comunicacionales, periodísticos o pedagógicos.

Esto implica pensar profesionales de la comunicación y la educación que desarrollen narrativas (con diferentes finalidades: informar, educar, entretener, exponer, exhibir, argumentar) con diferentes lenguajes (escritos, sonoros, audiovisuales, informáticos) y que sean accesibles para cualquier persona. Por eso es necesario aprender a editar textos, audios, imágenes y videos y también tener nociones básicas de programación, aunque no se trabaje habitualmente con ellos. Quizás las demandas de estos perfiles profesionales con nuevas habilidades también pongan en discusión el curriculum y los planes de estudio de las instituciones educativas.

El propósito fundamental consistió, entonces, en aportar fundamentos tecnológicos, comunicacionales y pedagógicos que permitan potenciar la producción de saberes, contenidos y recursos digitales en proyectos y ámbitos dedicados a la comunicación, el periodismo, la innovación educativa, la alfabetización multimodal y la apropiación social del conocimiento.

\section{Bibliografía}

Albarello F. (2011). Leer/navegar en internet. Las formas de lectura en la computadora. Buenos Aires: La Crujía.

Boczkowski, P.; Mitchelstein, E. y Matassi, M. (2018). News comes across when I'm in a moment of leisure: Understanding the practices of incidental news consumption on social media. New Media \& Society. Recuperado de https://doi.org/10.1177/1461444817750396

Castells, M. (1999). La era de la Información (Vol. 1): Economía, sociedad y cultura. La sociedad Red. Buenos Aires: Siglo XXI editores.

Cope, B. y Kalantzis, M. (2010). Gramática de la multimodalidad. Boletín de la Asociación Andaluza de Bibliotecarios, 98-99, pp. 93-154. 
Drigo, M. O. (2007). Comunicação e cognição: semiose na mente humana. Porto Alegre: Editorial Sulina.

Hjarvard, S. (2008). The mediatization of society. A theory of the media as agents of social and cultural change. Nordicom Review, 29(2), 105-134.

Hjarvard, S. (2016). Mediatización: La lógica mediática de las dinámicas cambiantes de la interacción social. La Trama de la Comunicación, 20, 235-252.

Hepp, A.; Hjarvard, S. y Lundby, K. (2015). Mediatization: theorizing the interplay between media, culture and society. Media, Culture \& Society, 37(2), 1-11.

Igarza, R. (2009). Burbujas de ocio. Nuevas formas de consumo cultural. Buenos Aires: La Crujía.

Irigaray, F. y Lovato, A. (2017). Comunicación post-convergente. Rosario: Editorial de la Universidad Nacional de Rosario.

Jenkins, H. (2008). Convergence Culture. La cultura de la convergencia de los medios de comunicación. Barcelona: Paidós.

Kaplún, G. (2002). Contenidos, itinerarios y juegos. Tres ejes para el análisis y la construcción de mensajes educativos. VI Congreso de la Asociación Latinoamericana de Investigadores de la Comunicación, Bolivia.

Kress, G. (2010). Multimodality. A social semiotic approach to contemporary communication. Nueva York: Routledge.

Lévy, P. (2007). Cibercultura. La cultura de la sociedad digital. Barcelona: AnthroposUniversidad Autónoma Metropolitana.

Maggio, M. (2016). Enriquecer la enseñanza. Buenos Aires: Editorial Paidos.

Manovich, L. (2006). El lenguaje de los nuevos medios de comunicación: la imagen en la era digital. Buenos Aires: Editorial Paidós.

Manovich, L. (2013). Software Takes Command. Nueva York: Bloomsbury Academic.

Marín Ossa, D. (2015). La educación mediatizada. Distancias y aproximaciones conceptuales en las metodologías de mediatización del conocimiento. Revista da FAEEBA-Educação e Contemporaneidade, 24(44), 41-53.

Masip, P. (2016). Rutinas periodísticas e internet en la información diaria. III Congrés Internacional Comunicació I Realitat, pp. 561-576.

Mendonça Jorge, T. (2013). Mutação no jornalismo: como a noticia chega a internet. Brasília: Editora Universidade de Brasília.

Nafría, I. (2017). La reinvención de The New York Times. Universidad de Texas: Knight para el Periodismo en las Américas. 
Peña Fernández, S.; Lazkano Arrillaga, I. y García González, D. (2016). La transición digital de los diarios europeos: nuevos productos y nuevas audiencias. Comunicar, XXIV(46), 2736.

Prigogine, I. y Stengers, I. (1979). La Nueva Alianza: Metamorfosis de la ciencia. Madrid: Editorial Alianza.

Raimondo Anselmino, N. (2012). La prensa online y su público: un estudio de los espacios de intervención y participación del lector en Clarín y La Nación. Buenos Aires: Teseo.

Rost, A.; Bernardi, M. T. y Bergero, F. (2016). Periodismo transmedia, la narración distribuida de la noticia. Neuquén: Publifadecs.

Schwartzman, G. y Odetti, V. (2011). Los materiales didácticos en la educación en línea: sentidos, perspectivas y experiencias. Proyecto Educación y Nuevas Tecnologías. Recuperado de http://www.pent.org.ar/publicaciones/materiales-didacticos-educacionlinea-sentidos-perspectivas-experiencias

Scolari, C. (2013). Narrativas transmedia: cuando todos los medios cuentan. España: Deusto.

Turpo Gebera, O. (2013). Convergencia tecnológica y pedagógica del blended learning: transiciones y perspectivas. Alteridad, 8, 128-143.

Vanderdorpe, C. (2003). Del papiro al hipertexto. Ensayo sobre las mutaciones del texto y la lectura. Buenos Aires: Fondo de Cultura Económica.

van Dijck, J. (2016). La cultura de la conectividad: una historia crítica de las redes sociales. Buenos Aires: Siglo Veintiuno editores.

Vassallo de Lopes, M. I. y Orozco Gómez, G. (coord.). (2014). Transmedia production strategies in television fiction. Obitel 2014. Porto Alegre: Sulina.

Verón, E. (2013). La semiosis social II. Ideas, momentos, interpretantes. Buenos Aires: Editorial Paidós.

Verón, E. (2015). Teoría de la mediatización: una perspectiva semio-antropológica. CIC. Cuadernos de Información y Comunicación, 20, 173-182.

World Wide Web Consortium (W3C) (2005). Introduction to Web Accessibility. Recuperado de http://bit.ly/1nBT4Vk 